\title{
UMA NOVA LEITURA DA VIDA DE CHARLES BAUDELAIRE: UMA RECEPÇÃO BIOGRÁFICA A PARTIR DA TRADUÇÃO DE SUA CORRESPONDÊNCIA
}

\author{
Gilles Jean Abes \\ Universidade Federal de Santa Catarina, Florianópolis, Santa Catarina, Brasil
}

\begin{abstract}
Resumo: O objetivo desse artigo é o propor uma outra leitura da vida do poeta Charles Baudelaire. De fato, a imagem do poeta das Flores do mal parece petrificada num discurso quase uníssono, presente em numerosas notas biográficas de traduções de grande circulação no Brasil, que faz eco ao ensaio de Ivan Junqueira, "A arte de Baudelaire" (1985). Ele afirma que o poeta, ainda criança, se revoltou com o segundo casamento da mãe, choque que marcou profundamente sua vida, que nunca se entendeu com o padrasto militar e seu meio-irmão, e que, depois de adulto, teria tido uma relação incestuosa com a mãe. Diante dessas afirmações, cuja argumentação se fundamenta sobretudo na correspondência do poeta, a proposta passa por um exame detalhado da formação daquela narrativa de vida. Nesse sentido, a tradução comentada de cartas deve, senão abalar aquele discurso, ao menos oferecer outra vereda para sua recepção biográfica.
\end{abstract}

Palavras-chave: Baudelaire; Biografia; Correspondência; Tradução.

\section{A NEW READING OF THE LIFE OF CHARLES BAUDELAIRE: A BIOGRAPHICAL RECEPTION FROM THE TRANSLATION OF HIS CORRESPONDENCE}

\begin{abstract}
The purpose of this article is to propose another reading of the life of the poet Charles Baudelaire. In fact, the image of the poet of the Flowers of Evil seems petrified in an almost unison speech, present in numerous biographical notes of translations of great circulation in Brazil, which echoes the essay by Ivan Junqueira, "The Art of Baudelaire" (1985). He affirms that the poet, as a child, was revolted with his mother's second marriage, a shock that profoundly affected his life, which was
\end{abstract}


never understood by his military stepfather and his half-brother, and who, as an adult, would have had an incestuous relationship with his mother. In the face of these statements, whose argument is based mainly on the correspondence of the poet, the proposal goes through a detailed examination of the formation of that narrative of life. In this sense, the commented translation of letters should, if not shake that discourse, at least offer another path for its biographical reception.

Keywords: Baudelaire; Biography; Correspondence; Translation.

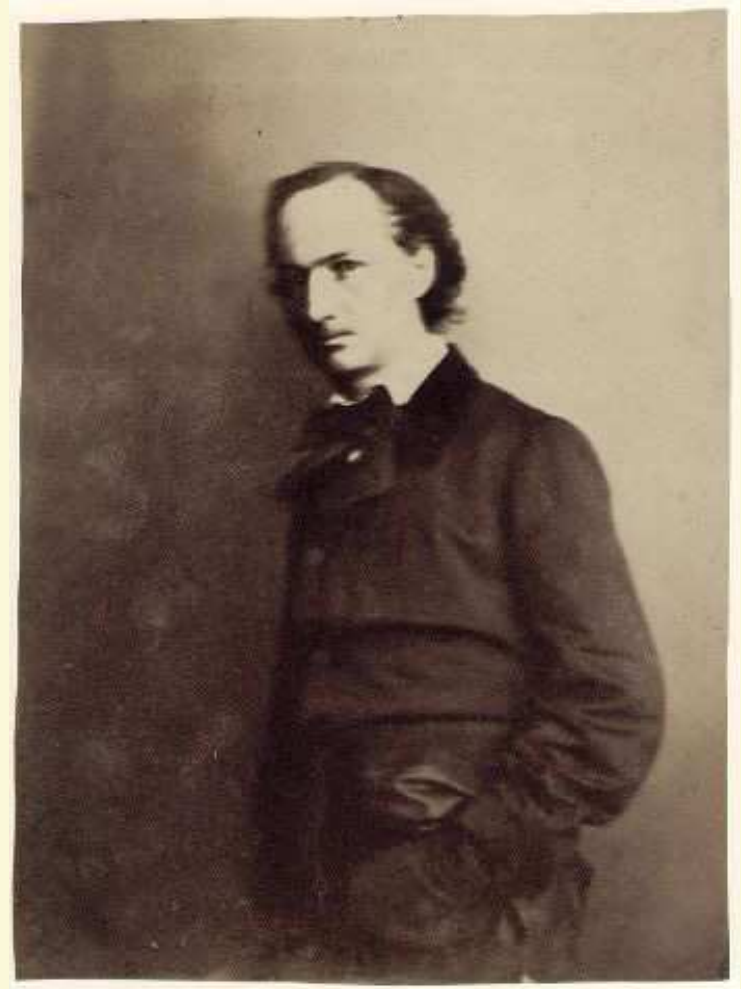

Baudelaire em 1855, fotografado por Nadar. Fonte: Musée d'Orsay. ${ }^{1}$

${ }^{1}$ Disponível em: http://www.musee-orsay.fr/fr/collections/catalogue-des-oeuvres/ notice.html?no_cache $=1 \&$ nnumid $=081376 \& \mathrm{cHash}=3447 \mathrm{c} 8108 \mathrm{c}$. Acesso em: 21.03.2017

Cad. Trad., Florianópolis, v. 38, n $^{0}$ esp. Baudelaire 150 anos, p. 70-97, ago-dez, 2018 
A imagem que podemos ter de uma vida humana é frequentemente fugidia, como podem observar pelo retrato de Baudelaire, fotografado pelo célebre Félix Nadar ${ }^{2}$, por volta de 1855. É uma vida composta de sombras que resistem a nossos esforços de explicá-la ou contá-la, sobretudo de maneira linear e homogênea. Este Baudelaire do retrato é o próprio da modernidade que ele mesmo definiu como transitória, efêmera, contingente, ainda que aprisionado na fotografia, busca fugir do olhar. Ao mesmo tempo, capturado por esta imagem, seu vulto está como que eternizado, imutável nas bordas e fibras da fotografia, outra face da modernidade de Baudelaire. Esta fotografia é simbólica, não somente do poeta enquanto personagem cuja narrativa de vida escapa a qualquer cerceamento absoluto, mas igualmente, na sua irredutibilidade, é sujeito às lendas criadas pelos olhares que ali se debruçam, como muito bem escreveu o próprio poeta em seu poema em prosa "As janelas": "Com seu rosto, com seu traje, com seu gesto, com quase nada recriei a história daquela mulher, ou antes, sua lenda, e às vezes, eu a conto a mim mesmo chorando."(BAUDELAIRE, 1975, p. 339) ${ }^{3}$

Proponho, neste artigo, escapar um pouco à lenda, e oferecer outra leitura possível da vida de Baudelaire a partir da tradução de suas cartas. De fato, o acesso à correspondência do autor reflete uma imagem diversa de algumas afirmações contundentes de baudelairianos, afirmações estas que formam um poderoso discurso que se tornou quase que um lugar comum. Não se trata, claro, de condenar os "biógrafos", mas antes de questionar esse discurso de uma história de vida que se assemelha a uma narrativa linear,

\footnotetext{
${ }^{2}$ Pseudônimo de Gaspard-Félix Tournachon, fotógrafo, caricaturista e jornalista nascido em Paris, no dia 5 de Abril de 1820. Nadar, como era chamada, fotografou boa parte das personalidades do século XIX, já que faleceu aos 89 anos - uma exceção para a época - em Paris, no dia 21 de Março de 1910.

3 Todas as traduções encontradas são de minha autoria, exceto menção contrária. O texto de partida se encontra em nota de rodapé. "Avec son visage, avec son vêtement, avec son geste, avec presque rien, j'ai refait l'histoire de cette femme, ou plutôt sa légende, et quelquefois je me la raconte à moi-même en pleurant.”
}

Cad. Trad., Florianópolis, v. 38, $\mathbf{n}^{0}$ esp. Baudelaire 150 anos, p. 70-97, ago-dez, 2018 
na qual, para cada palavra e gesto, um sentido restrito - nas duas acepções do termo - (como significação e um percurso com início, meio e fim) foi atribuído: a vida como um conjunto coerente de acontecimentos. Ao mesmo tempo, esses gestos serviram de dispositivo de arranque para uma narrativa de vida romantizada e lendária, estreitamente ligada à ideia do poeta maldito. É como se houvesse a necessidade que, para ser um(a) grande poeta, cada palavra ou movimento precisasse ser amplificado pelos biógrafos, com gestos singulares, por exemplo, mostras de rebeldia do poeta maldito. Em suma, o revolucionário da obra ligada ao revolucionário da vida. Surge nesse ponto uma preocupação de não interpretar a existência do poeta, enquanto pessoa, diretamente sob as luzes da obra. Como disse a poeta Adrienne Rich:

Há uma tendência em tratar poemas - pelo menos em certos círculos - como uma espécie de documentação sobre a vida do poeta, como talvez uma espécie de autobiografia, e eu quero começar abordando essa noção. Sinto-me muita próxima de Wallace Stevens quando diz que 'poesia é a ficção suprema', que um poema não é uma fatia da vida do poeta, embora, obviamente, emirja de lugares intensos da vida do poeta, de sua consciência e experiência. Mas Muriel Rukeyser tem uma frase - que escreveu quando era muito jovem e ela já sabia disso; A frase é 'Inspire experiência, expire poesia'. Há nela um senso de transmutação: algo deve acontecer entre o inspirar experiência e o expirar poesia. Algo foi transformado, não somente em palavras, mas em algo novo. ${ }^{4}$ (RICH, 1993, p. 252-253)

4 “There's a tendency to treat poems - at least in certains circles - as a sort of documentation on the poet's life, as perhaps a kind of autobiographie, and I want to start by addressing that notion. I feel very strongly with Wallace Stevens that 'poetry is the supreme fiction,' that a poem is not a slice of the poet's life, although it obviously emerges from intense places in the poet's life and consciousness and experience. But Muriel Rukeyser has a line - she wrote it when she was very young and she already knew this; the line is 'Breathe in experience, breathe out poetry.' There is a sense of transmutation: something has to happen

Cad. Trad., Florianópolis, v. 38, n $^{0}$ esp. Baudelaire 150 anos, p. 70-97, ago-dez, 2018 
Não se deveria, em qualquer interpretação de um texto literário, passar diretamente da vida do autor, ou da autora, para uma explicação da obra, como leitura fechada na biografia. Só podemos fazê-lo com extrema cautela e com a consciência de que algo de novo se transformou entre o "inspirar experiência" e o "expirar poesia”. O contrário também parece uma abordagem metodologicamente equivocada. Adaptando a belíssima frase de Muriel Rukeyser, há uma discrepância entre o "inspirar poesia" e o "expirar vida" . Nisso, a correspondência, como matéria híbrida, entre confissão e simulação, entre autobiografia e autoficção, exige talvez ainda mais atenção.

Outro problema é a compreensão dos acontecimentos de uma vida, pela construção do espaço no qual estes se dão e onde os outros agentes estão envolvidos. Como diz Bourdieu, no artigo "A ilusão biográfica": "quem pensaria em evocar uma viagem sem ter a ideia da paisagem na qual ela se realiza?" (AMADO; FERREIRA, 2005, p. 190) Assim, não é possível falar da vida de Baudelaire, sem melhor compreender a vida de uma família burguesa no século XIX, as vidas da Senhora e do coronel Aupick, de Alphonse Baudelaire e outros agentes fundamentais no conjunto de relações com o poeta.

Assim sendo, a minha proposta é a de analisar a recepção biográfica do poeta Charles Baudelaire no Brasil a partir da tradução de sua correspondência e de questioná-la, oferecendo outra leitura possível. O embate inicial se deu com um importante estudo que precede a tradução de maior circulação das Flores do mal. O ensaio de Ivan Junqueira, “A arte de Baudelaire” (1985), simboliza perfeitamente um discurso quase uníssono que afirma uma suposta revolta do jovem Baudelaire com o segundo casamento da mãe, seu comportamento rebelde desde jovem, seu desentendimento com o padrasto militar e o meio-irmão, Alphonse, e até mesmo insinuações de um relacionamento incestuoso com a mãe.

between the breathing in of experience and the breathing out of poetry. It has been transformed, not only into words but into something new."

Cad. Trad., Florianópolis, v. 38, $\mathrm{n}^{0}$ esp. Baudelaire 150 anos, p. 70-97, ago-dez, 2018 
Importa observar que esse longo ensaio de Junqueira precede sua tradução de As flores do mal (1985), publicada pela Nova Fronteira - tradução consagrada e de grande circulação - que está igualmente presente no volume único Poesia e Prosa, publicado em 1995 pela editora Nova Aguilar, assim como na obra Baudelaire, Eliot, Dylan Thomas: três visões da modernidade, lançada pela Record em 2000. Portanto, trata-se aqui de um discurso replicado em diferentes livros sobre o poeta, que amplia seu poder de alcance.

Vejamos um excerto central para nossa questão:

A problemática espiritual de Baudelaire deita suas mais fundas raízes no substrato de um conflito familiar que remonta à primeira infância do poeta. Contribuem de forma decisiva para isso os dois casamentos [...] enquanto que o padrasto do poeta, o general Jacques Aupick, contava 39 quando, em novembro de 1828, resgatou Caroline de sua curta viuvez. Baudelaire, então com sete anos, jamais absorveu esse golpe, tanto assim que, pouco depois, como nos informa François Porché, escreveria: 'Quando se tem um filho como eu, não se casa outra vez.' Mais espantoso ainda é o que se lê em carta que o poeta enviou à mãe a 6 de maio de 1861 (37 anos depois!) e na qual escreve: 'Há em minha infância uma época de amor apaixonado por ti; escuta e lê se [sic] receio. Jamais falei tanto disso a ti. Lembro-me de um passeio de fiacre; saías de uma casa de saúde em que estavas exilada, e me mostraste, para pensar que pensaste em teu filho, desenhos à caneta que fizeste para mim. Julgas que tenho uma memória terrível? Mais tarde, a praça de Saint-Andrédes-Arts e Neuilly. Longas caminhadas, ternuras sem fim!' Ocioso acrescentar o que quer que seja. O texto fala por si. Estivesse vivo em fins do século XIX, Baudelaire teria sido um dos mais paradigmáticos pacientes de Freud, a própria encarnação do complexo de Édipo. (JUNQUEIRA, 1995, p. 61-62)

Em outra passagem importante, Junqueira afirma: 
É também perturbador, já aqui em plano muito mais amplo, o que registra o poeta no fragmento 18 de Projéteis: ' $\mathrm{O}$ gosto precoce pelas mulheres. Confundia o cheiro das peles com o odor da mulher. Lembro-me... Enfim, amava minha mãe por sua elegância. Era portanto um dândi precoce.' Bastariam esses poucos textos para confirmar à saciedade [sic] o conflito em que mergulhara o pequeno Charles, que pouquíssimo privou [sic] da intimidade do próprio pai (ao morrer Joseph-François, Baudelaire tinha apenas seis anos), que jamais se entendeu com o irmão mais velho (Alphonse, filho do primeiro casamento de Joseph-François), que se viu destituído do amor materno após a chegada do general Aupick e que por este foi tratado, não propriamente de forma odiosa ou distante, mas sob as severas imposições do único critério de que dispunha o padrasto para educação de uma criança: o da disciplina militar. (1995, p. 62)

A voz de Junqueira faz eco a de Jean-Paul Sartre com seu Baudelaire (1947). Vejamos o que diz Sartre:

Quando sua mãe morreu, Baudelaire tinha seis anos, ele vivia na adoração de sua mãe; fascinado, envolto em atenções e cuidados, ele ainda não sabia que existia como pessoa, mas sentia-se unido ao corpo e ao coração de sua mãe por um tipo de participação primitiva e mística; perdia-se na doce tepidez de seu amor recíproco; havia apenas um lar, uma família, um casal incestuoso. (SARTRE, 2000, p. 18). ${ }^{5}$

\section{Sartre prossegue:}

5 "Lorsque son père mourut, Baudelaire avait six ans, il vivait dans l'adoration de sa mère ; fasciné, entouré d'égards et de soins, il ne savait pas encore qu'il existât comme une personne, mais il se sentait uni au corps et au cœur de sa mère par une sorte de participation primitive et mystique ; il se perdait dans la douce tiédeur de leur amour réciproque ; il n'y avait là qu'un foyer, qu'une famille, qu'un couple incestueux."

Cad. Trad., Florianópolis, v. 38, $\mathbf{n}^{0}$ esp. Baudelaire 150 anos, p. 70-97, ago-dez, 2018 
Em novembro de 1828, essa mulher tão amada volta a casar-se, com um soldado; Baudelaire é colocado num pensionato. É dessa época que data sua famosa 'fissura'. Crépet cita a esse respeito uma nota significativa de Buisson: 'Baudelaire era uma alma muito delicada, muito fina, original e terna, que se fissurou ao primeiro contato com a vida.' Havia, nessa existência, um acontecimento que não pudera suportar: o segundo casamento de sua mãe. (Idem, p. 18-19). ${ }^{6}$

Junqueira cita François Porché, e seu La vie douloureuse de Charles Baudelaire (1926). Sartre, por sua vez, nomeia Eugène Crépet, que recolheu uma lembrança de Jules Buisson, camarada de Baudelaire do tempo da pensão Bailly de 1839 a 1841. Na verdade, a citação inteira é: "Baudelaire era uma alma muito delicada, muito fina, original e terna, mas feminina e frágil que se fissurou ao primeiro contato com a vida." (grifo meu) (PICHOIS, ZIGLER, 1987, p. 142). Sartre parece ter censurado a associação do feminino com a ideia de sexo frágil, associação que para nós hoje é absurda (ou deveria). O gesto é curioso porque também não problematiza completamente essa ideia, bastante romântica e equivocada - ainda mais para um filósofo que é o companheiro de Simone de Beauvoir! -, de uma alma delicada que não resistiu ao primeiro choque com a vida. A personalidade do poeta, ou pior, uma suposta "natureza" feminina, repentinamente, se assemelha a uma porcelana de Limoges, um cristal Baccarat ou um vaso Ming. Nada mais equivocado, pois esta pretendida fragilidade, parado-

6 "En novembre 1828 cette femme tant aimée se remarie à un soldat; Baudelaire est mis en pension. De cette époque date sa fameuse 'fêlure'. Crépet cite à ce sujet une note significative de Buisson: 'Baudelaire était une âme très délicate, très fine, originale et tendre, qui s'était fêlée au premier choc de la vie.> Il y avait, dans son existence, un évènement qu'il n'avait pu supporter : le second mariage de sa mère."

7 "Baudelaire était une âme très délicate, très fine, originale et tendre, mais féminine et faible qui s'était fêlée au premier choc de la vie."

Cad. Trad., Florianópolis, v. 38, n $^{0}$ esp. Baudelaire 150 anos, p. 70-97, ago-dez, 2018 
xalmente, é atestada por um testemunho, ele mesmo frágil em seu estado e constituição. O elemento importante da formação desse discurso tem assim base num testemunho, o de Jules Buisson, camarada que conviveu algum tempo com Baudelaire, em sua juventude, relato dado a Crépet em 1868, portanto, muitos anos após o período da pensão Bailly, o que nos leva a refletir sobre a questão da memória e do próprio testemunho, ainda mais quando este passa a ser a chave de leitura da vida de Baudelaire. Aliás, Jules Buisson é o mesmo sujeito que teria testemunhado e ouvido o Baudelaire gritar que "Era preciso fuzilar o general Aupick" nas barricadas da revolução de 1848. (PICHOIS; ZIEGLER, 1987, p. 257) O testemunho em si é questionado por Pichois, pois há outro, de Charles Toubin (com quem fundou o efêmero jornal Le Salut Public), que aloca a cena de manhã, enquanto Buisson a descreve como ocorrida no final da tarde. A divergência, que se situa numa informação relativamente simples (a cena aconteceu de manhã ou no final da tarde), deveria apontar para a fragilidade do testemunho. Podemos, a partir desse evento, fazer três leituras: Jules Buisson deturpou a cena; ou o relato do gritou foi pura provocação, bem ao estilo baudelairiano; ou, finalmente, o poeta, num momento de exaltação, fervor e raiva, de fato pronunciou o fuzilamento contra o padrasto. É verossímil porque naquele momento, o coronel Aupick havia se tornado o símbolo do conservadorismo burguês que Baudelaire tanto detestava. Ainda assim, esse acontecimento não pode ser compreendido num movimento linear, mas dentro de uma relação de tensões contraditórias. Para finalizar sobre o acontecimento, nas cartas de Baudelaire, aparentemente não há referência a esse relato.

O livro de Porché é igualmente fundamental para entender o discurso que vai se construindo sobre a vida de Baudelaire. Se não levarmos em conta o título, La vie douloureuse de Charles Baudelaire [A vida dolorosa de Charles Baudelaire], o capítulo III - "Première connaissance avec l'enfer" [Primeiro contato com o inferno], é bastante revelador. 
Da mesma maneira como a felicidade bruscamente apoderara-se de Charles, uma catástrofe abominável se abateu sobre sua cabeça. Quê? sua mãe está morrendo? Não, mas há agora instantes em que a criança, em seu ódio, teria preferido que estivesse morta. [...] Charles sofre pela primeira vez, e de um sofrimento cujos amargores do rancor, a queimadura do ciúme mesclam-se às dores lancinantes de uma ferida envenenada.

Sua mãe o traiu. Vai casar-se novamente. [...] A alegria, plenitude um instante entrevista, apaga-se para sempre da vida de Baudelaire. Você está me ouvindo: para sempre. Já é hora, e quão cedo chegou! em que, em seu destino, algum pássaro sinistro, semelhante ao corvo de Edgar Poe, bate as asas e diz: nevermore. (PORCHÉ, 1926, p. 20) ${ }^{8}$

O tom é teatral (no pior sentido) e ecoará em outros baudelairianos.

Mas, além do ensaio de Junqueira, quais outras vozes formam esse discurso no Brasil? Em outra tradução consagrada, a de Guilherme de Almeida, reeditada pela Editora 34 (2010), Manuel Bandeira afirma na apresentação da coletânea: "Charles Baudelaire (1821-1867) teve a infelicidade de perder o pai aos seis anos e nunca se ter entendido com o padrasto, o que resultou na separação de sua mãe." Da mesma forma, o posfácio "Sobre Charles Baudelaire”, de autoria de Marcelo Tápia, informa:

8 "De même que le bonheur brusquement avait saisi Charles, une catastrophe épouvantable s'abat sur sa tête. Quoi ! sa mère meurt ? Non, mais il est, à présent, des minutes où l'enfant, dans sa rage, préférerait qu'elle fût morte. [...] Charles souffre pour la première fois, et d'une souffrance où les aigreurs de la rancune, la brûlure de la jalousie se mêlent aux élancements d'une plaie empoisonnée. Sa mère l'a trahi. Elle va se remarier. [...] La joie, cette plénitude un instant entrevue, s'efface à jamais de la vie de Baudelaire. Vous m'entendez bien : à jamais. C'est l'heure, et combien tôt venue ! où, dans sa destinée, quelque oiseau sinistre, pareil au corbeau d'Edgar Poe, bat de l'aile et dit : nevermore"

Cad. Trad., Florianópolis, v. 38, n $^{0}$ esp. Baudelaire 150 anos, p. 70-97, ago-dez, 2018 
Charles Pierre Baudelaire nasce em Paris a 9 de abril de 1821. Seu pai, Joseph-François Baudelaire, amante de pintura e ele mesmo pintor, morre seis anos depois, em 1827. Um ano mais tarde, sua mãe, Caroline Archimbaut-Dufays, casa-se em segundas núpcias com o militar Jacques Aupick, homem de caráter rígido com quem Baudelaire jamais se entenderá e que representará para ele um obstáculo em seu relacionamento com a mãe. (ALMEIDA, 2010, p. 137)

No prefácio intitulado "Brota uma flor no jardim de Baudelaire", de Álvaro Faleiros, que precede a última tradução das Flores publicada em 2011, obra de Mário Laranjeira pela Martin Claret, o discurso é o mesmo: "Sua relação com o padrasto nunca foi boa e Baudelaire, depois de ter levado uma vida mundana dos 18 aos 20 anos, foi enviado de barco às Índias por ele.” (BAUDELAIRE, 2011, p. 12)

Outro tradutor famoso, José Paulo Paes, afirma, em sua Poesia erótica (2006): “Depois de perder o pai quando contava apenas seis anos de idade, Charles Baudelaire (1821-1867) jamais se conformou com o segundo casamento de sua mãe, que o levou desde cedo a atitudes de rebeldia." (2006, p. 192)

Na introdução do Spleen de Paris, de Dorothée de Bruchard, na edição de 1988:

Já é da infância que Baudelaire traz em si, concreto e consciente, o sentimento de solidão e marginalidade: o segundo casamento de sua mãe (que, 34 anos mais-moça que o marido, ficara viúva aos 33) com o coronel Aupick, homem de espírito estreito, perturba-o profundamente e transforma seus anos de infância e adolescência, que passou interno num colégio de Lyon, numa longa e melancólica seqüencia de revoltas. (BAUDELAIRE, 1988, p. 07)

No prefácio de outra tradução dos poemas em prosa, publicada em 2010 pela Martin Claret, Oleg Almeida afirma: 
Baudelaire [...] seguiu uma via crucis de mágoas, doenças e privações, vindo a falecer aos quarenta e seis anos, mudo e hemiplégico, órfão de sua época e refém de seu enorme talento. A curta e trágica vida dele transcorreu numa sociedade [...]. Charles Baudelaire tinha a possibilidade de alcançar os ápices da hierarquia estatal, tornando-se destacado político ou diplomata, mas abriu mão dessa perspectiva impulsionado tanto por algumas circunstâncias de ordem pessoal - morte do pai, que amaria, segundo casamento da mãe e aversão ao padrasto, entre outras - quanto pela rebeldia própria da juventude. (ALMEIDA a , 2010, p. 09-10)

Além desses textos, todos paratextos inseridos em traduções mais ou menos consagradas, temos uma biografia de Baudelaire, escrita por Jean-Baptiste Baronian, cuja tradução em português foi publicada pela L\&PM em 2010. Na seção intitulada "A chegada do mau", sobre a reação do jovem Charles ao segundo casamento, Baronian afirma:

O mau, por sua vez, ainda não chegou, mas sua presença já pode ser sentida. Algumas noites, Caroline Baudelaire deixa-se levar por um misterioso indivíduo que ainda não tem nome, que é apenas uma sombra, uma imponente silhueta ao crepúsculo. [...]

No início, ele não fica nem muito feliz, nem muito perturbado com a brusca mudança imposta pelo casamento inesperado de sua mãe. Ele, aliás, também não é hostil ao homem que acaba de tomar o lugar de seu pai - apesar de considerá-lo bastante dissimulado em suas atitudes e bastante severo em suas relações com seu entourage. [...]

Charles começa a resistir, a não aceitar suas recomendações, a contrariar suas ordens. Depois, progressivamente, passa a detestá-lo. E logo a odiá-lo. Menos por acreditar que Jacques Aupick lhe roubara o amor materno do que por ser incapaz de concordar com sua maneira de ser, de pensar e de viver.

Cad. Trad., Florianópolis, v. 38, n $^{0}$ esp. Baudelaire 150 anos, p. 70-97, ago-dez, 2018 
Nessas difíceis condições, é impossível não culpar o padrasto por todos os males, não considerar que ele seja o empecilho "para crescer à vontade".

Impossível não tomá-lo justamente pelo mau .

O que Jacques Aupick não é. (2010, p. 14-16)

Percebemos não somente um tom melodramático e sensacionalista, à exemplo de François Porché, como, novamente, a imagem de um jovem Charles que se revolta aos poucos com o padrasto. Este continua a figura central, que toma as decisões e ao qual o poeta se opõe. Por outra lado, Baronian ao menos minimiza a importância do segundo casamento na ruptura com a família, mas o faz a partir de seu ponto de vista, ou seja, não aprofunda as relações de Baudelaire com sua família durante sua infância e juventude. $\mathrm{O}$ biógrafo continua replicando o discurso de que Baudelaire culpou Aupick, se colocando com uma sorte de juiz que procura em parte redimir o militar. Não questiona se de fato Baudelaire provou esse ódio para com o padrasto e minimiza sua relação com ele na juventude.

Outra obra sobre o poeta, lançada em tradução em 2012 pela Companhia das Letras, é o livro de Roberto Calasso, A folie Baudelaire. $\mathrm{O}$ texto do autor e editor toscano começa assim:

\begin{abstract}
Baudelaire propunha encontros clandestinos no Louvre à sua mãe Caroline: 'Em Paris, é onde melhor se pode conversar; é aquecido, pode-se esperar ali sem se enfadar e, por outro lado, é o lugar de encontro mais conveniente para uma mulher. ${ }^{9} \mathrm{O}$ medo do frio, o terror ao tédio, a mãe tratada como uma amante, a clandestinidade e a decência conjugadas no ambiente da arte: somente Baudelaire podia combinar esses elementos quase sem perceber, com total naturalidade. (2012, p. 11)
\end{abstract}

${ }^{9}$ Carta de Charles Baudelaire a Madame Aupick, 16 de dezembro de 1847.

Cad. Trad., Florianópolis, v. 38, $n^{0}$ esp. Baudelaire 150 anos, p. 70-97, ago-dez, 2018 
A tese de Renata Philippov, "Edgar Allan Poe e Charles Baudelaire: Trajetórias e maturidade estética e poética”, defendida na USP (2004), engrossa novamente o coro desse discurso sobre a biografia de Baudelaire:

O autor francês nasce em 9 de abril de 1821, filho do segundo casamento de um pintor amador com uma mulher bem mais nova do que o marido. Em 1827, seu pai morre, o que marcaria profundamente a infância e adolescência de Baudelaire. Em 1828, um ano após ter ficado viúva, sua mãe casa-se novamente, fato esse jamais bem aceito pelo escritor francês. Do ambiente ligado às artes e à livre expressão de sentimentos, passa-se, então, à austeridade militar. De fato, o padrasto, General Aupick, sempre teria uma relação conflituosa com Baudelaire: sua austeridade militar e sua objetividade não combinavam com a liberdade de espírito artístico livre do enteado, estabelecendo-se, assim, um eterno conflito de mentalidades. (2004, p. 59)

Outra fonte interessante e que, por falta de espaço, não vou aqui reproduzir, é a internet e seus blogs. Lá também, o discurso sobre a vida de Baudelaire é o mesmo. Fica o convite para conferir essa afirmação. Após essa abordagem arqueológica, ao estilo foucaultiano, de busca pela formação de um discurso sobre a vida de Baudelaire e de que maneira se deu sua recepção no Brasil, precisamos nos voltar para os textos, sobretudo a correspondência. Já que, como disse Junqueira, "o texto fala por si”, examinemos então o que as mesmas fontes revelam se abordadas de maneira mais ampla - cartas de infância e juventude, não somente de Baudelaire, mas também entre os familiares - e, sobretudo, agregando à nossa leitura crítica uma tentativa de compreensão das mentalidades da época: a mentalidade e a melhor compreensão da vida privada de uma família burguesa do século XIX. No mais, é preciso problematizar as noções de "memória" e de "biografia", elementos fundamentais para a nossa argumentação.

Cad. Trad., Florianópolis, v. 38, n $^{0}$ esp. Baudelaire 150 anos, p. 70-97, ago-dez, 2018 
O jovem Charles escreveu mais de 40 cartas ao meio-irmão, Alphonse Baudelaire, entre os anos de 1832 a 1841. Nelas, chama Alphonse de "irmão", dá notícias sobre sua viagem a Lyon e sobre vários acontecimentos na cidade, manda lembranças para Théodore, irmão de Félicité (esposa de Alphonse), a quem chama de "irmã", assim como para toda a família e amigos dos familiares, fala sobre seus resultados escolares, informa Alphonse sobre seus gostos em literatura para que lhe presenteie com livros, cobra que o irmão lhe escreva, e sobretudo, chama várias vezes o seu padrasto de "papai”.

Vejamos um exemplo de carta para Alphonse na qual Charles conta as surpresas que sua mãe e ele estão preparando para receber o coronel Aupick de volta em casa.

[Lyon,] 25 de abril de 1832, quinta-feira ${ }^{1}$.

Meu irmão,

Mamãe é muito preguiçosa para escrever, assim, me exortou a escrever antes do dia primeiro do mês, justificando o pedido com o motivo que era preciso te agradecer pelas certidões que mandou. É por isso que te agradeço assim como ela, e estamos ambos encantados pela tua boa saúde.

Desculpa sua preguiça ao pensar que está cercada de cortinas, porque vamos nos mudar; nosso novo endereço será rua de Auvergne, $n^{\circ} 6$. Pode ver que dessa vez não esqueci meu endereço.

Realmente o medo do cólera te faz esquecer a gramática francesa; entretanto, eu não quero citar seus erros, porque ver o mais novo ensinar a ortografia ao mais velho seria o mundo de ponta cabeça.

Papai parte amanhã de Grenoble e estará em Lyon sextafeira. Mamãe prepara surpresas para ele; da minha parte, comprei dois objetos que darei para ele escolher. Esses dois objetos são, em primeiro lugar, um esgravatador de ouvido e um esgravatador de dentes de marfim, esgravatador de dentes que me custou 10 soldos, e, em segundo lugar, uma pena inglesa da Clays em um estojo de madeira das ilhas.

Cad. Trad., Florianópolis, v. 38, $n^{0}$ esp. Baudelaire 150 anos, p. 70-97, ago-dez, 2018 
Também fiz fósforos, para encher os pequenos vasos de chiffonnage $e^{10}$ que mamãe fez, dos quais mando um exemplar. É moda em Lyon fazê-los assim; já excelo nessa arte, e será uma surpresa para papai; coloquei brancos, azuis, vermelhos. Mamãe encheu o outro vaso com esgravatadores de dentes.

Não sei como demorei tanto para contar minha colocação de décimo terceiro em tema. Encarrego-te de mandar lembranças da minha parte a minha irmã, a Théodore e a toda a família. Boa noite.

Responda-me o mais rápido possível.

Seu irmãozinho.

CH. BAUDELAIRE. (1973, p. 07) $)^{11}$

\begin{abstract}
${ }^{10}$ Vasos factícios feitos com pedaços de tecido, característicos da decoração dessa época. (N. do Trad.)

11 "Mon frère, Maman est très paresseuse pour écrire, de manière qu'elle m'a engagé à écrire avant le premier du mois en appuyant cela de cette raison qu'il fallait te remercier des actes que tu lui avais envoyés. C'est pourquoi je te remercie ainsi qu'elle, et nous sommes enchantés tous les deux de ta bonne santé. Excuse sa paresse en pensant que les rideaux l'entourent, parce que nous allons déménager; notre nouvelle adresse sera rue d'Auvergne, $\mathrm{n}^{\circ} 6$. Tu vois que cette fois je n'ai pas oublié mon adresse. Réellement la peur du choléra te fait oublier la grammaire française ; pourtant je ne veux pas te citer tes fautes, parce que voir le cadet apprendre l'orthographe à l'aîné serait le monde renversé. Papa part demain de Grenoble et sera à Lyon vendredi. Maman lui prépare des surprises ; pour moi, j'ai acheté deux objets et lui donnerai à choisir. Ces deux objets sont en premier lieu un cure-oreille et cure-dent en ivoire, cure-dent qui me coûte 10 sous, et en deuxième lieu une plume anglaise de Clays dans un étui de bois des îles. J'ai fait aussi, pour remplir les petits vases de chiffonnage qu'a faits maman, des allumettes dont je t'envoie un exemplaire. C'est la mode à Lyon d'en faire comme cela ; j'excelle déjà dans cet art, et ce sera une surprise pour papa ; j'en ai mis des blanches, des bleues, des rouges. Maman a rempli l'autre vase de curedents. Je ne sais pas comment j'ai tardé jusqu'à présent pour te dire ma place de treizième en thème. Je te charge de dire bien des choses de ma part à ma soeur, à Théodore et à toute la famille. Bonsoir. Réponds-moi le plus tôt possible. Ton petit frère, CH. BAUDELAIRE."
\end{abstract}

Cad. Trad., Florianópolis, v. 38, $\mathbf{n}^{0}$ esp. Baudelaire 150 anos, p. 70-97, ago-dez, 2018 
Em aproximadamente 18 de junho de 1839, Baudelaire escreve uma carta aos pais, endereçada ao padrasto, que estão tratando do ferimento do coronel nas águas termais de Bourbonne-les-bains (Lorraine), da qual destaco a seguir alguns excertos.

Fico muito agradecido pela carta que acaba de me escrever; é tão boa, tão afetuosa. Eis, francamente, o motivo que, há oito dias, me leva sempre a adiar ao dia seguinte para escrever; fazem alguns dias que não trabalho, e como devo falar do que faço, dizia a mim mesmo que antes de escrever, queria voltar a trabalhar para ter algo bom a contar.

Mas você me repreende com tanta bondade e indulgência em sua carta que, na verdade, é melhor confessá-lo que adiar novamente para escrever ou escrever uma carta mentirosa. E fique tranquilo, na primeira vez em que eu lhe escreverei, terei coisas boas a contar. [...]

Tem a bondade de perguntar-me quais projetos tenho; pois sim, tenho alguns, sabe que sempre tenho projetos, que eu sou um espírito para projetos; há momentos em que penso no futuro, e então estou repleto de coisas que gostaria de contar àqueles que me amam; mas me permita adiar isso para outro dia; o Sr. Lasègue vai retornar e me perguntar o que penso sobre um livro no qual ainda não toquei.

Amanhã escrevo a mamãe. Agradeço por ter me falado de sua saúde; se seus sofrimentos podem levar ao bem, me alegro quase pelos seus sofrimentos; aliás sempre tenho esperanças, mesmo que fosse preciso de um milagre para te curar.

CHARLES. $\left(1973\right.$, p. 72-73) ${ }^{12}$

12 “Je te remercie bien de la lettre que tu viens de m'écrire ; elle est si bonne, si
affectueuse ; voilà, franchement, le motif qui depuis huit jours m'a fait remettre
sans cesse au lendemain pour vous écrire ; c'est que je n'ai pas travaillé depuis
quelques jours, et comme il faut que je vous parle de ce que je fais, je me disais
qu'avant de vous écrire, je voulais me remettre à travailler pour avoir du bien à
dire de moi. Mais tu me grondes avec tant de bonté et d'indulgence dans ta lettre
que, ma foi, il vaut mieux avouer cela que remettre encore à t'écrire ou écrire une
lettre menteuse. Et sois tranquille, la première fois que je t'écrirai, j'aurai du bien
à dire de moi. [...] Tu as la bonté de me demander quels projets je fais; eh oui,

Cad. Trad., Florianópolis, v. 38, $\mathbf{n}^{0}$ esp. Baudelaire 150 anos, p. 70-97, ago-dez, 2018 
No dia 12 de agosto de 1839, Baudelaire conclui seu segundo grau, obtendo o diploma do baccalauréat, depois de ter sido aprovado no exame. No dia 13 de agosto, o jovem Charles manda uma carta a Aupick para anunciar a boa notícia e, ao mesmo tempo, para desejar-lhe parabéns "de fils à père" [de filho para pai], como ele mesmo escreve, por ter sido nomeado general de brigada.

\begin{abstract}
Acabo de ver uma boa notícia e tenho uma boa para te anunciar. Li essa manhã tua nomeação no Le moniteur, e eu sou bachelier $^{13}$ desde ontem à noite às 4 horas. Meu exame foi bastante medíocre, exceto o latim e o grego muito bem - foi o que me salvou. Estou bem feliz por tua nomeação - de filho para pai, não são felicitações banais como todas aquelas que receberá. Eu estou feliz, porque te vi o suficiente para saber o quanto isso é merecido; pareço bancar o homem, e te parabenizar como se fosse teu igual ou superior. - Assim para dizer simplesmente, saiba que estou bem contente. (BAUDELAIRE, 1973, p. 77) ${ }^{14}$
\end{abstract}

\begin{abstract}
j'en fais, tu sais que j'en fais toujours, que je suis un esprit à projets, moi; il y a des moments où je fais l'avenir, et alors je suis plein de choses que je voudrais raconter à ceux qui m'aiment; mais permets-moi de remettre cela à un autre jour; $\mathrm{M}$. Lasègue va rentrer et me demander ce que je pense d'un livre auquel je n'ai pas touché. Demain, j'écris à maman. Je te remercie de m'avoir parlé de ta santé; si tes souffrances peuvent tourner à bien, je me réjouis presque que tu souffres; d'ailleurs j'espère toujours, fallut-il un miracle pour te guérir. CHARLES."

${ }^{13}$ O termo "bachelier" corresponde, no sistema educacional francês, a um aluno que obteve seu diploma do baccalauréat, exame do último ano do ensino médio que pode dar acesso ao ensino superior. Não é equivalente ao vestibular e existe até hoje. [N. do Trad.]

14 "Je viens de voir une bonne nouvelle et j'en ai une bonne à t'annoncer. J'ai lu ce matin ta nomination dans Le Moniteur, et je suis bachelier depuis hier soir à 4 heures. Mon examen a été assez médiocre, excepté le latin et le grec - fort bien c'est ce qui m'a sauvé. Je suis bien heureux de ta nomination - de fils à père, ce ne sont pas des félicitations banales comme toutes celles que tu recevras. Moi je suis heureux, parce que je t'ai vu assez souvent pour savoir combien cela t'était dû; j'ai l'air de faire l'homme, et de te féliciter comme si j'étais ton égal ou ton supérieur. - Ainsi pour dire simplement, sache que je suis bien content.”
\end{abstract}

Cad. Trad., Florianópolis, v. 38, n $^{0}$ esp. Baudelaire 150 anos, p. 70-97, ago-dez, 2018 
Em 12 de agosto de 1839, Baudelaire já tem 18 anos de idade, e na sua correspondência não há sinal algum de revolta com a família ou o padrasto. Ao contrário, pouco tempo antes, em 1838, Charles, sua mãe e Aupick realizaram uma viagem pelo sul da França que teria inspirado o poema em prosa Le Gâteau ( $O$ Bolo). Aliás, é bom lembrar que, em julho do mesmo ano, Charles escreveu uma carta ao padrasto contando sua primeira experiência como crítico de arte amador quando foi visitar o museu de Versalhes com sua escola. ${ }^{15}$

O jovem Charles antes revela seus problemas para estudar, as punições que recebe por conversar com os colegas de sala, uma revolta dos alunos contra um bedel que bateu num colega. Nada, absolutamente nada além de palavras que parecem demonstrar uma criança e um jovem agradável, preocupado com a família, e até relativamente sincero com a falta de vontade de estudar. Por outro lado, Charles revela-se agitado em sala, o que lhe valeu alguns pensums, como ele mesmo diz, tem excelente potencial, mas demonstra ocasionalmente comportamentos excêntricos, segundo os professores, e pouca vontade para estudar, quando não preguiça, termo que ele mesmo emprega várias vezes. Nas palavras da mãe, o que a desespera é que o filho deixa sempre para fazer suas obrigações na última hora. Em outras palavras, as atitudes de Baudelaire não seriam tão diferentes de um jovem de classe média de nossos tempos. Precisamos, no entanto, destacar o contexto das escolas da época, muito menos permissivas no que tange a comportamentos "inadequados" e regras de conduta. Outra aspecto fundamental é a noção de honra, muito mais aguda naquele contexto, sobretudo para uma família burguesa como a Baudelaire/Aupick. Segundo Jacques Donzelot, na sua obra A polícia das famílias,

o sentimento moderno da família teria surgido nas camadas burguesas e nobres do Antigo Regime estendendo-se, pos-

15 Vide artigo: ABES, Gilles Jean. Charles Baudelaire e sua primeira crítica de arte. In: Scienticia Traductionis, n. 7, 2010.

Cad. Trad., Florianópolis, v. 38, $n^{0}$ esp. Baudelaire 150 anos, p. 70-97, ago-dez, 2018 
teriormente, através de círculos concêntricos, para todas as classes sociais, inclusive o proletariado do fim do século XIX. (1986, p. 11)

É fundamental observar que ao círculo sagrado da família, um dos pilares da sociedade da época, e seu patrimônio, agrega-se a noção de honra que tem um papel simbólico. Michelle Perrot, no quarto volume da História da vida privada, nos diz sobre a família do século XIX:

Tudo que arranha sua reputação, que mancha seu nome, é uma ameaça. Cerra fileiras contra o estranho que lhe faz uma ofensa. O erro comprometedor de um membro seu mergulha-a num constrangimento cruel. Solidariedade na reparação, punição do tribunal familiar, exclusão, cumplicidade do silêncio: todas as reações são possíveis. Ai daquele, porém, que traz a desgraça! (2009, p. 250)

Nesse sentido, sua expulsão do Liceu Louis-Le-Grand, em abril de 1839, pode ser interpretado de duas formas. Charles provocou a ira e a desonra da família ou, mesmo que tenha desesperado a mãe e o padrasto, foi em parte perdoado pela sua retidão ao não denunciar o seu colega de turma, apesar das ameaças do diretor. Marcel Ruff, em seu Baudelaire (1957), sustenta justamente que o coronel, por ser militar, perdoou facilmente o gesto de lealdade que originou a expulsão.

A grande ruptura, na verdade, ocorre aos poucos, com diversos acontecimentos entre os anos de 1839 a 1842, que constitui um período crucial na vida de Baudelaire: portanto, não possui uma origem. Além de demonstrar alguns comportamentos de rebeldia próprios à sua idade, passa a viver longe da família, frequentando inclusive a pensão Bailly. Livre e sem a vigilância dos pais, Charles prova sua primeira experiência literária, levando uma vida de boemia, contraindo não somente algumas dívidas 
como uma doença venérea. Dessa vez, é Alphonse quem perdoará o irmão mais novo, que solicitará a ajuda de um amigo farmacêutico, o Sr. Guérin, com consulta e dinheiro para comprar os remédios, conforme indicam três cartas de 20 de novembro, 02 e 03 de dezembro de 1839.

A partir de 1841, os problemas se agravam, as dívidas aparecem e conhecemos a sequência da história: o Conselho de Família, a viagem, o retorno antecipado e a tutela cautelar no final do ano de 1844. No entanto, pouco se diz sobre as esperanças da família de que a experiência da viagem e o afastamento das más influências pudessem metamorfosear Baudelaire ao ponto de voltar a ser aquele jovem cheio de promessas e de "um comércio encantador", conforme a expressão de Alphonse em uma carta para a família Baudelaire/Aupick, datada de 30 de abril de 1840. Como revela outra missiva do dia 19 de janeiro de 1842, pouco antes da chegada de Charles, dessa vez de Alphonse Baudelaire para o general.

Compreendo toda a ansiedade que deve lhes causar o retorno de Charles, as preocupações que seu futuro pode causar e, sobretudo, as tristezas da Senhora Aupick. [...]

Hoje procuremos acolher Charles como a criança pródiga que retorna em sua família: ou reconheceu a extensão de seus erros e o temor de confessá-los o retém e o impede de escrever, ou não mudou. Neste último caso, seria preciso estudar suas ideias, ver se são falsas por má aplicação de seus conhecimentos ou em decorrência de alguma anomalia na organização. [...] Pese esse meio com o Sr. Ancelle. Bastaria talvez para reservar um futuro para ele, sem recorrer a outros meios que me repugnariam tanto quanto ao senhor. (BANDY; PICHOIS, 1957, p. 60-62)

Alphonse se refere aqui à tutela cautelar como último recurso que pretendem usar para resgatar Baudelaire de sua vida de boemia e garantir seu futuro. A reação da família não parece assim tão afastada do modo de agir de uma família de classe média no século 
XXI. Não obstante, há um agravante que é justamente o valor que se atribui à noção de honra. Baudelaire não se contenta em viver de sua escrita, quer ser poeta inspirado nos "esgotos de Paris", como afirmou seu padrasto em uma carta endereçada a Alphonse em 19 de abril de 1841.

Há, conforme penso, conforme Paul e Labie, urgência em arrancá-lo do paralelepípedo escorregadio de Paris. Sugeriram-me de fazê-lo empreitar uma longa viagem por mar, às Índias, na esperança que assim desambientado, arrancado às detestáveis relações, e na presença de tudo aquilo que poderia estudar, poderia voltar à razão, e retornar poeta talvez, mas poeta tendo extraído suas inspirações em outras fontes do que os esgotos de Paris. (PICHOIS; ZIEGLER, 1987, p. 137-138)

O então general Aupick, ao saber da situação, bem depois de Alphonse, faz um empréstimo pessoal de 3.000 francos para pagar as dívidas de Charles, inicia discussões com Alphonse e amigos próximos para obter sua opinião sobre a melhor decisão a tomar. Dia 14 de junho de 1841, ocorre o Conselho de Família na presença do general, de Alphonse, dos amigos Paul Pérignon, Théodore Olivier, Jean Labie, Pierre Zédé, Louis Émon e Edmond Blanc, sob a presidência de um juiz de paz. Aupick obtém assim a autorização de pedir emprestado, nos bens de Charles, o valor de 4.000 francos necessários para pagar as despesas da viagem. Charles é enviado para Fontainebleau, na casa do irmão, e depois para Creil, ao norte de Paris, na casa de um amigo do general, o tenente-coronel Dufour, onde foi inclusive muito bem recebido, para esperar a partida do navio Paquebot-des-Mers-du-Sud.

Ao retornar, tempos depois, dia 09 de abril de 1842, Baudelaire reafirma aos pais que deseja ser autor. Todavia, como vimos, o maior problema não é a profissão, mas sim as dívidas, a vida mundana, a relação com uma mulher supostamente atriz, de origem caribenha, a "Vênus negra", como Baudelaire a chamava, com

Cad. Trad., Florianópolis, v. 38, n $^{0}$ esp. Baudelaire 150 anos, p. 70-97, ago-dez, 2018 
quem nunca casou e não teve filhos, o que na época deve ter provocado muita rejeição por parte dos familiares. Os temas da poesia de Baudelaire e o escândalo que provocou certamente veio piorar a situação. Daí o silêncio imposto na família, como mencionou Michelle Perrot, com a proibição de pronunciar o nome de Charles Baudelaire. Daí a marginalidade em que o poeta se encontrou, tendo como única pessoa de sua família para compartilhar seus sucessos literários, suas angústias, projetos, sofrimentos... a mãe, a Senhora Aupick. Daí o encontro no museu, conforme a carta de Baudelaire a mãe em 16 de dezembro de 1848, porque simplesmente fora banido pelos outros familiares e onde até mesmo o padre, que frequentava a casa, nas palavras de Baudelaire, era seu inimigo. Um museu, ao contrário do que diz Calasso, parecia um lugar conveniente para encontrar sua mãe, uma mulher fora do domínio privado, em tempos de puritanismo exacerbado.

Em suma, o enfrentamento entre os conceitos de trabalho, sucesso e honorabilidade aparecem como chaves para o entendimento dessa fratura. Certamente, o casal Aupick e sua esposa, ambos eram órfãos, Alphonse e os amigos da família agiram com base em suas experiências de vida, com sua ambição e seus próprios valores, os quais se embatiam brutalmente com a visão de arte e de mundo do filho que queria ser poeta e compor "flores do mal". É, aliás, um tem que aparece várias vezes na correspondência do poeta com sua mãe.

Além disso, há uma necessidade de compreender uma narrativa de vida, ainda mais uma vida distante da nossa, de forma não-linear, repleta de atos contraditórios, aleatórios e irracionais, assim como é, de fato, uma vida humana. Como diz Bourdieu:

Produzir uma história de vida, tratar a vida como uma história, isto é, como o relato coerente de uma seqüência de acontecimentos com significado e direção, talvez seja conformar-se com a ilusão retórica, uma representação comum da existência que toda uma tradição literária não deixou e não deixa de reforçar. Eis por que é lógico pedir auxílio àqueles

Cad. Trad., Florianópolis, v. 38, n $^{0}$ esp. Baudelaire 150 anos, p. 70-97, ago-dez, 2018 
que tiveram que romper com essa tradição no próprio terreno de sua realização exemplar. Como diz Allain Robbe-Grillet [sic], 'o advento do romance moderno está ligado precisamente a esta descoberta: o real é descontínuo, formado de elementos justapostos sem razão, todos eles únicos e tanto mais difíceis de serem apreendidos porque surgem de modo incessantemente imprevisto, fora de propósito, aleatório'. (AMADO, FERREIRA, 2005, p. 185)

Ora, o que observamos, inclusive com base em Claude Pichois e Marcel Ruff, cujos estudos biográficos destoam dos encontrados em nosso país, é que o discurso atual quer absolutamente dar significação e um sentido linear à vida de Baudelaire com base em um testemunho que, como sabemos, é bastante subjetivo e questionável. No mais, é preciso ler as cartas no seu conjunto, inclusive as cartas enviadas entre os familiares, com cautela, sem perder de vista o contexto dessas relações complexas. Eis a famosa paisagem mencionada por Bourdieu, assim como os agentes, na qual a viagem da vida de Baudelaire acontece. Na mesma carta tão citada por Junqueira e outros baudelairianos, de 6 de maio de 1861, Baudelaire revela sentimentos contraditórios - como de fato são numa vida humana - e diz:

Mais tarde você sabe qual atroz educação seu marido quis me dar; tenho quarenta anos e não penso nos colégios sem dor, tampouco no temor que meu padrasto me inspirava. No entanto, eu o amei, e aliás, tenho hoje sabedoria o suficiente para fazer justiça a ele. Mas, enfim, ele foi obstinadamente inábil. Quero escorregar rapidamente, porque vejo lágrimas em seus olhos. ${ }^{16}$ (grifo nosso) (BAUDELAIRE, 2003, p. 240)

\footnotetext{
16 "Plus tard tu sais quelle atroce éducation ton mari a voulu me faire; j'ai quarante ans et je ne pense pas aux collèges sans douleur, non plus qu'à la crainte que mon beau-père m'inspirait. Je l'ai cependant aimé, et d'ailleurs j'ai aujourd'hui assez de sagesse pour lui rendre justice. Mais enfin il fut opiniâtrement maladroit. Je veux glisser rapidement, parce que je vois des larmes dans tes yeux."
}

Cad. Trad., Florianópolis, v. 38, n $^{0}$ esp. Baudelaire 150 anos, p. 70-97, ago-dez, 2018 
A vida de Baudelaire se assemelha hoje, entre nós, a um eco de um histórico eco, que veio engrandecer e propagar sua lenda. Percebo, nas notas biográficas encontradas em diferentes paratextos que acompanham suas obras traduzidas, uma vida aparelhada a um fio condutor cuja problemática possui uma origem bem definida: $o$ choque com o segundo casamento da mãe. Todavia, não é somente a vida de Baudelaire, a maneira como é contada, que estamos debatendo, mas a forma de narrar qualquer vida humana. Neste sentido, amparo-me novamente em Bourdieu:

\begin{abstract}
É significativo que o abandono da estrutura do romance como relato linear tenha coincidido com o questionamento da visão da vida como existência dotada de sentido, no duplo sentido de significação e de direção. Essa dupla ruptura, simbolizada pelo romance de Faulkner $O$ som e a fúria, exprime-se com toda a clareza na definição da vida como anti-história proposta por Shakespeare no fim de Macbeth: 'É uma história contada por um idiota, uma história cheia de som e de fúria, mas desprovida de significação.' (2005, p. 185)
\end{abstract}

Que desperte, portanto, um novo interesse pela correspondência de Charles Baudelaire e que, nessa leitura, o discurso lugar-comum sobre a biografia do poeta seja abalado. Com a tradução destas epístolas, talvez uma nova narrativa de vida possa aflorar, e até mesmo influenciar a recepção poética e a tradução de sua obra. Que doravante seja também contada como uma anti-história, com base em um vitral estilhaçado - sua correspondência - com suas imagens lacunares. Que não relatem uma trajetória romantizada, mas antes um caleidoscópio de gestos e poses contraditórios, descontínuos, sem coerência nem fio condutor, com mudanças de humor, de sentimentos, de estados de espírito e de direção, com acontecimentos e atitudes incompreensíveis, que possam também ser desprovidos de significação e de grandeza, para tocar mais de perto uma vida real, a vida como ela é: irredutível, como Baudelaire. 


\section{Referências}

ALMEIDA, Guilherme de. Flores das Flores do mal de Baudelaire. Tradução e notas de Guilherme de Almeida; ilustrações de Henri Matisse; apresentação de Manuel Bandeira; posfácio de Marcelo Tápia; edição bilingue. São Paulo: Ed. 34, 2010.

ANDRADE, Carlos Drummond de; ANDRADE, Mario de. Carlos \& Mário: Correspondência completa entre Carlos Drummond de Andrade (inédita) e Mário de Andrade. 1924-1945. Rio de Janeiro: Bem-Te-Vi, 2002.

BANDY, W.T., PICHOIS, C. Baudelaire devant ses contemporains. Paris: Rocher, 1957.

BARONIAN, Jean-Baptiste. Baudelaire. Tradução de Julia de Rosa Simões. Porto Alegre: LP\&M, 2010.

BAUDELAIRE, Charles. Correspondance I, II: 1832-1860/ 1860-1866. Paris: Gallimard, 1973.

Poesia e Prosa: volume único. Edição organizada por Ivo Barroso. Rio de Janeiro: Nova Aguilar, 1995.

- Correspondance. Choix et présentation de Claude Pichois et Jérôme Thélot. Paris: Gallimard, 2003.

. Pequenos poemas em prosa. Tradução de Dorothée de Bruchard. Florianópolis: Editora da UFSC, 1988.

. Poesia e prosa: volume único. Charles Baudelaire; edição organizada por Ivo Barroso. - Rio de Janeiro: Nova Aguilar, 1995.

Cad. Trad., Florianópolis, v. 38, $\mathbf{n}^{0}$ esp. Baudelaire 150 anos, p. 70-97, ago-dez, 2018 
Claret, 2011.

. As flores do mal. Tradução de Mário Laranjeira. São Paulo: Martin . Pequenos poemas em prosa. Tradução de Oleg de Almeida. São Paulo: Martin Claret, 2011.

BOURDIEU, Pierre. A ilusão biográfica. In: FERREIRA, Marieta de Moraes; AMADO, Janaína. Usos e abusos da história oral. $6^{\mathrm{a}}$ ed. - Rio de Janeiro: Editora Fundação Getúlio Vargas, 2005.

CALASSO, Roberto. A folie Baudelaire. Tradução de Joana Angélica d'Avila Melo. São Paulo: Companhia das Letras, 2012.

DONZOLET, Jacques. A polícia das famílias. Tradução de M. T. da Costa Albuquerque; revisão técnica de J. A. Guilhon Albuquerque. Rio de Janeiro: Edições Graal, 2 a Ed., 1986.

PAES, José Paulo. Poesia erótica. Seleção, tradução e notas de José Paulo Paes. São Paulo: Companhia das Letras, 2006.

PERROT, Michelle (Org.). História da vida privada, 4: da Revolução Francesa à Primeira Guerra. Tradução de Denise Bottmann e Bernardo Joffily. São Paulo: Companhia das Letras, 2009.

PHILIPPOV, Renata. Edgar Allan Poe e Charles Baudelaire: Trajetórias e maturidade estética e poética. Tese. São Paulo: USP, 2004.

PICHOIS, Claude (Org.). Lettres à Baudelaire. Publiées par Claude Pichois. Neuchâtel: Éditions de la baconnière, 1973.

PICHOIS, Claude; ZIEGLER, Jean. Baudelaire. Paris: Julliard, 1987.

PORCHÉ, François. La vie douloureuse de Charles Baudelaire. Paris: Plon, 1927.

Cad. Trad., Florianópolis, v. 38, n $^{0}$ esp. Baudelaire 150 anos, p. 70-97, ago-dez, 2018 
RICH, Adrienne. Adrienne Rich's poetry and prose. Stanford: Ed. Stanford University, 1993.

RUFF, Marcel, A. Baudelaire. Paris: Hatier, 1957.

SARTRE, Jean-Paul. Baudelaire. Paris: Gallimard, 2000.

Recebido em: 12/08/2018

Aceito em: 13/10/2018

Publicado em dezembro de 2018

Gilles Jean Abes. E-mail: gillesufsc@gmail.com

ORCID: https://orcid.org/0000-0001-9063-1997

Cad. Trad., Florianópolis, v. 38, n $^{0}$ esp. Baudelaire 150 anos, p. 70-97, ago-dez, 2018 